\title{
É possível utilizar o "método" Warburgiano na busca de uma arte homoafetiva?
}

César Silva Barcelos Júnior?

DOI 10.20396/eha.vil4.3332

\section{Introdução}

O fato de a nudez masculina ser rarefeita na arte, em comparação com a mesma temática feminina, levanta questionamentos a respeito de como a sociedade atual, que ainda possui raízes no patriarcado, preserva a imagem masculina para ser usada em determinados motivos e situações mais "nobres" na História da Arte. Enquanto fotos e quadros de homens sem roupa, que por algum motivo possam ser lidas com certa conotação sensual, estiveram, durante algum tempo, relegados a um submundo artístico ou como peças de estudo, sem valor no mercado e sem espaço nos museus e galerias.

A concepção deste artigo deu-se a partir da leitura da tese Representações do Masculino nas Artes Visuais: performance, pintura e fotografia do Professor Doutor Shahram Afrahi, apresentada ao Departamento de Pós-Graduação em Artes Visuais da Universidade de Brasília. Foram consultadas bibliografias que desenvolvem as questões ortodoxas a respeito da nudez na arte e da nudez masculina: O Nu, de Kenneth Clark e Adam-The Male Figure in Art, de Edward Lucie-Smith, respectivamente. O livro Nude Men -from 1800 to the present day, editado por Tobias G. Natter e Elisabeth Leopold foi utilizado como "balizador" do raciocínio empregado no artigo, especialmente a introdução de Tobias G. Natter (Forword: the long shadow of the fig leaf). A obra de James M. Saslow, Pictures and Passions - A History of Homosexuality in the Visual Arts contribui na forma fonte de referências e, de certo modo, como "espinha dorsal" do trabalho.

1 Aluno especial no PPCA UFES até julho de 2019, MBA em História da Arte pela Universidade Estácio de Sá, Graduado em Ciências Econômicas pela Universidade Federal do ES. 
Sobre o "método" de Warburg

Aby Warburg foi um historiador da arte, estudioso de antropologia e psicologia. Filho de banqueiros judeu-alemães que abriu mão da sua primogenitura nos negócios da família para se dedicar aos estudos e experiências que culminaram, após sua morte, na constituição do Instituto Warburg de pesquisa da Antiguidade Clássica e que atualmente encontra-se vinculado à Universidade de Londres. Em 1891, Aby Warburg, apresenta sua tese de doutorado em que estuda duas pinturas de Sandro Botticelli, O Nascimento de Vênus e A Primavera² ${ }^{2}$ Nessa tese ele identifica a "energia" da Ninfa na imagem de uma figura feminina que, com seus cabelos e roupas esvoaçantes, passa a informação do movimento de um ser etéreo, de uma presença mística. A identificação dessa energia é ressaltada, durante sua tese, em diversas outras imagens encontradas em situações, lugares e épocas diferentes como em poemas, na literatura, em moedas, afrescos, gravuras e imagens talhadas em sarcófagos. Utilizando-se desse olhar apurado em diversas imagens, Warburg desenvolveu o Atlas Mnemosyne, onde imagens de obras de arte, fotografias e textos, que se assemelham em determinados pontos, são dispostos em pranchas de forma a compor uma miríade de informações que conduzam ao um "núcleo duro" cultural que sobrevive ao tempo e ao espaço, e que se manifesta através de lembranças antigas; que ativam uma "energia" inconsciente. Para designar essa energia, Warburg cunha o termo pathosformels, a fórmula de pathos, que indica uma concentração de energia afetiva, muitas vezes inconsciente, em determinadas imagens e que tem sua origem na Antiguidade. Aby Warburg não deixou um método de estudo das imagens formalmente constituído ${ }^{3}$, mas a construção (ou montagem) de seu pensamento pode ser utilizada em uma epistemologia multidisciplinar que compreende, por exemplo, literatura, artes, antropologia, filosofia, psicologia e semiótica.

Neste artigo, o método de Warburg é entendido como uma forma de escolher, montar e analisar um grupo de imagens e assim identificar temas, formas, símbolos e mensagens que thes sejam comuns. Ao encontrar esse possível "denominador comum" nessas imagens (que podem ser de diferentes autores, épocas e locais), inicia-se um estudo aprofundado e multidisciplinar desse assunto que permeia essas representações. A partir de tais estudos é possível identificar a persistência de uma imagem no tempo, uma sobrevivência de registros antigos; à potência dessa

\footnotetext{
2 WARBURG, Aby. Histórias de fantasmas para gente grande: escritos, esboços e conferências. 1. ed. Organização: Leopoldo Waizbort; tradução: Lenin Bicudo Bárbara, Companhia das Letras, São Paulo, 2019, p. 24

3 Por esse motivo, no título deste artigo, coloquei o método warburguiano entre aspas. Destaque que não usarei no decorrer do trabalho.
} 
imagem, Warburg chama de nachleben der antiques ${ }^{4}$. É interessante ressaltar que, nesse ponto, Aby Warburg desenvolve uma forma de estudo da história em que as imagens são colocadas no centro da pesquisa e de uma forma não cronológica. Nesse caso, o que mais importa são as semelhanças encontradas e o que tais repetições querem mostrar ou se abarcam alguma mensagem. Nesse momento, o método aproxima-se das teorias do inconsciente de Freud e do inconsciente coletivo e arquétipos de C.G. Jung. Lissovsky, citando Rampley, enuncia em seu artigo sobre Aby Warburg:

O método de montagem de Warburg, por sua vez, "refletiria seu entendimento da cultura como espaço de memória, do qual símbolos visuais e outros funcionam como um arquivo de memórias justapostas". ${ }^{5}$

É nesse espaço que existe entre o observador e a imagem que residem "fantasmas" e "espectros" antigos, cheios de informações codificadas, adormecidas e esperando para serem rememoradas. Assim, "os símbolos seriam os veículos, na memória social, da carga energética vinculada à experiência emocional das gerações passadas" ${ }^{\prime \prime}$. A escolha desse método para a análise das imagens que constam neste artigo, e para a busca das marcas deixadas pela homoafetividade na história da arte, reside na identificação com o rompimento dos limites do formalismo e da análise puramente estética e visual das obras de arte. Em Warburg, não se trata de identificação de um estilo, mas do "exame da tradição cultural" (ACAMBEN):

[...] caracterizada como uma recusa do método estilístico-formal dominante na história da arte no final do século XIX e como um deslocamento do foco da investigação da história dos estilos e da avaliação estética para os aspectos pragmáticos e iconográficos da obra da arte $[\ldots] .^{7}$

A história de uma imagem traz também a história de uma cultura, ressaltando problemas históricos e éticos. Estrutura-se como uma "psicologia histórica da expressão humana". A essa disciplina, Giorgio Agamben chama de "inominada", pois seu autor não encontrou um nome definitivo e seus estudiosos não chegam a um consenso quanto a esse nome devido sua abrangência.

A carga emocional contida nas imagens e que dialoga com o inconsciente humano é o elo do

\footnotetext{
4 A tradução desse termo é polêmica. Encontramos na literatura alguns autores utilizando sobrevivência da imagem , outros, pós-vida da imagem , e há o vida póstuma das imagens. Utilizarei neste artigo simplesmente sobrevivência da imagem . A escolha da tradução desse termo, nachleben der antique, ressalta até mesmo qual abordagem o autor está realizando dos estudos de Aby Warburg.

5 LISSOVSKY, Maurício. A vida póstuma de Aby Warburg: por que seu pensamento seduz os pesquisadores contemporâneos da imagem? Boletim do Museu Paraense Emílio Goeldi, Ciências Humanas, Belém, v. 9, n. 2, mai-ago. 2014, p. 316.

6 LISSOVSKY, 2014, p.312.

7 ACAMBEN, Giorgio. A potência do pensamento: ensaios e conferências. Tradução de Antônio Guerreiro. Editora Autêntica, Belo Horizonte, 2015, p.112.
} 
método warburguiano de análise de obras de arte com a homoafetividade ${ }^{8}$ e objetivo central desta investigação que se inicia. O que chama atenção é, quando das análises dos trabalhos de artistas que possuem em sua biografia fortes traços de comportamentos homoafetivos, não serem levados em consideração os fatores psicológicos de uma sexualidade/afetividade muitas vezes reprimida ou inviabilizada de ser vivida em sua plenitude.

\section{Sobre a homoafetividade grega}

Na análise da imagem do kouros, na Antiguidade Grega, observa-se a estátua de um jovem belo, de corpo proporcional, rosto sereno que servia de oferenda de beleza aos deuses nos templos. Como beleza, essa civilização entendia a manifestação física do eu interior, da virtude e do que é correto.

Mas não são apenas os aspectos perceptíveis através dos sentidos que exprimem a Beleza do objeto: no caso do corpo humano assumem um papel relevante também as qualidades da alma e do caráter, que são percebidas mais com os olhos da mente do que com aqueles do corpo. ${ }^{9}$

Os gregos da antiguidade possuíam uma conexão profunda com o corpo masculino e mostrar a nudez desse corpo era mostrar a virtude do homem. Essa relação de admiração por esse corpo era também manifesta em suas relações sociais. A sociedade ateniense, por exemplo, entendia a homoafetividade masculina como algo benigno, lúdico e que compunha o aprendizado e a entrada na vida adulta dos jovens cidadãos de Atenas. É importante ressaltar que, na Grécia Antiga, somente os homens, livres eram considerados cidadãos. As interações entre esses homens aconteciam nas palestras ou ginásios, e era comum que praticassem esportes (como corridas e lutas) completamente nus. Daí a fascinação grega pelo corpo masculino. Outras interações entre esses homens estão documentadas nas pinturas de centenas de vasos gregos: cortejos, toques e abraços, ofertas de presentes e atos sexuais.

Representações de Ganimedes e Titono, mortais lendários cuja beleza excitava até mesmo as divindades, nos permitem definir os critérios de beleza masculina, e podemos observar que os mesmos critérios são satisfeitos na representação de deuses eternamente jovens

\footnotetext{
8 O termo homoafetividade é utilizado para ressaltar os sentimentos de carinho e afeição entre pessoas de mesmo sexo, ampliando o conceito de homossexualidade que passa a designar as vivências sexuais propriamente ditas.

9 ECO, Humberto. História da beleza.Tradução Eliana Aguiar. Record, Rio de Janeiro, 2010, p.41.
} 
(notadamente Apolo) e de meninos ou jovens representados como sendo perseguidos, cortejados ou abraçados por amantes humanos comuns. Disto é possível derivar uma justificativa para considerar como pin-ups o grande número de jovens, retratados em várias poses em vasos de todos os tipos, especialmente o jovem isolado (normalmente nu, às vezes vestindo-se ou despindo-se) que ocupa a superfície interior de um vaso raso. ${ }^{10}$

A admiração grega pelo corpo masculino é assimilada, de certa forma, pela estatuária romana e deixada de lado durante a ascensão e consolidação do Cristianismo. Devido às diversas contradições existentes no interior dessa seita as representações do corpo humano nu durante a Idade Média foram reduzidas e sua retomada com maior potência ocorreu durante o Renascimento.

O artista renascentista retoma os valores humanistas da Grécia Antiga nas artes e na filosofia. O corpo humano volta a figurar como algo belo e admirável, desta vez não somente como fruto da atividade física, mas para imprimir a centralidade do homem no universo da renascença. De Leonardo da Vinci tem-se a figura do Homem Vitruviano, com seu corpo proporcional, bem torneado e assumindo essa centralidade universal.

\section{O Davi de Miguel Ângelo Buonarroti}

A figura escolhida para ser justaposta ao Kouros grego é o Davi de Miguel Ângelo Buonarroti. Essa estátua de mármore de Carrara de 5,16m de altura foi encomendada pela Opera del Duomo e pela Guida de Lã de Florença, no ano de 1501 . O contrato realizado com o artista não estabelece qual figura seria retirada do bloco de mármore, apenas expressa que seria "o gigante". Importa, nesse momento, ressaltar a história do personagem escolhido pelo artista: Davi, na mitologia bíblica e judaica, foi um rei judeu com grandes habilidades guerreiras e artísticas, além de vencer diversas batalhas, era também harpista e poeta. Um de seus feitos clássicos é a batalha contra o gigante filisteu, Golias, em que Davi, após desfazer-se da armadura que atrapalha seu caminhar, vence o gigante utilizando uma funda e uma pedra. Outro fato interessante da vida de Davi era sua relação com o personagem Jônatas que, na narrativa mitológica, é colocada como bastante íntima, onde ambos vivem uma ligação de almas e um amor mais intenso que o sentido em relação às mulheres.

A imagem de um jovem, belo, com um corpo absolutamente extraordinário é ofertada a uma cidade como o símbolo de sua força e renovação política. Essa obra foi realizada por um ar- 
tista homossexual em um momento histórico e artístico de retomada da estética clássica grega. O tema escolhido é de um dos personagens mais emblemáticos da mitologia judaico-cristã, mas que possui ao mesmo tempo semelhanças com a mitologia pagã grega (um poeta e tocador de harpa, pastor de ovelhas e sua profunda relação homoafetiva com Jônatas). Warburg escreve em seu texto sobre Dürer e a Antiguidade Italiana:

Mas a Antiguidade veio em seu socorro pela via italiana, não só instigando-o dionisiacamente, mas também o decantando apolineamente: o Apolo de Belvedere pairava diante de seus olhos quando procurava a medida ideal do corpo masculino, e ele comparou a verdadeira natureza às proporções de Vitrúvio. ${ }^{11}$

Não obstante o excerto acima referir-se a outro artista, é possível captar a tradução do espírito da época de Miguel Ângelo.

Outra obra que corrobora com a argumentação explicitada é o Davi de Donatello, confeccionada 20 anos antes do Davi de Miguel Ângelo, e que possui uma forte energia homoafetiva. Segundo a literatura consultada, é possível conjecturar que Miguel Ângelo tenha visto essa obra antes de começar o seu Davi. Na estátua de Donatello, Davi é retratado muito jovem (ainda não possui os pelos pubianos), de pé em um contrapposto sobre a cabeça de Golias e com uma espada na mão direita. Não obstante essa descrição, essa figura encontra-se em uma pose que possui uma suave languidez que nos remete ao corpo feminino. Essa sensação é realçada na análise da parte posterior da estátua e a região do baixo ventre. Sua musculatura é bem menos evidente e no todo, guarda semelhanças com as imagens de Eros, o deus do amor. A energia encontrada no Davi de Miguel Ângelo é a da virilidade do jovem que se faz homem: musculatura proeminente de um atleta, veias ressaltadas e rosto tenso, com olhar firme a encarar o inimigo. A aura que paira em ambas as obras é a mesma exaltada e admirada pelo erastés na Antiguidade Clássica Grega: o jovem imberbe que já possui a altura de um adulto e o atleta viril que lutava nas palestras. O tratamento que cada artista deu ao baixo ventre dessas obras é digno de nota: Donatello utiliza-se de formas arredondadas muito próprias das imagens femininas, enquanto Miguel Ângelo ressalta o volume do oblíquo externo, mais de acordo com as imagens masculinas nuas do Período Helenístico. Pois "o corpo distorcido foi sempre reconhecido como o veículo do pathos" (Clark, 1969, p.190).

A precisão dos pormenores contribui aqui, apenas para acentuar o seu significado e torná -los inteligíveis. A sede de triunfo que o David irradia é a do próprio Miguel Ângelo, crista-

11 WARBURG, 2019, p. 94. 
lizada em sua obra. Essa energia latente que faz dilatar os músculos e incha as veias é sua própria energia. [...] $]^{12}$

\section{O banhista de Thomas Eakins}

Eakins nasceu no estado da Filadélfia, nos Estados Unidos, em 1844. Foi desenhista, artista e anatomista. Estudou desenho na École dês Beaux-Arts de Paris. Sua abordagem do nu masculino é a naturalista, sem qualquer idealização. Chama atenção a pose do banhista em pé no quadro The Swimming Hole ${ }^{13}$, de 1885; sua imagem atrai o olhar do espectador dessa obra, o relaxamento de sua musculatura e o contorno de suas costas e a nádegas, estão em destaque. A composição piramidal fala por si. A pose do banhista remete-nos ao Davi de Donatello, citado anteriormente, embora mesmo com toda a sinuosidade da figura no quadro de Eakins, este não passa a mesma carga de languidez que a de Donatello. A composição das três figuras sobre as pedras remete às sensações homoafetivas que são objetos de estudo neste artigo; são poses, olhares, gestos e toda uma aura que indica a tal leitura. Thomas Eakins teve uma relação de amizade com o poeta Walt Whitman e ambos artistas possuíam um traço em comum em sua poética, o interesse por uma profunda camaradagem entre homens que, por sua vez, está ligado a uma sobrevivência de um comportamento que foi bastante enfatizado na Antiguidade Grega.

It was inevitable that Whitman's ideas about male comradeship were recognized by many as declarations of homosexuality, attracting supporters from America and from Europe. Though Whitman was reluctant to acknowledge the homosexual content in public there is little doubt about the emotionshe described. Judging by his paintings, Eakins was also well aware of Whitman's ideas [...]. ${ }^{14}$

É possível que a poesia Song ofMyself de Whitman, publicada pela primeira vez em 1855, tenha inspirado a pintura de The Swimming Hole. O verso 11, da versão de 1895 dessa poesia, trata de homens jovens banhando-se, tomando sol na praia e uma "mão poética" que passa por seus corpos molhados, acompanhando o escorrer da água.

\footnotetext{
12 ARBOUR, Renée. Miguel Ângelo. Editora do Minho, Barcelos, 1985, p. 44.

13 O título original dessa pintura é Swimming, e encontra-se, assim nomeada, no Amon Carter Museum of American Art. A bibliografia consultada para este artigo utilizou o título The Swimming Hole, ao qual também utilizei.

14 COOPER, 1986, p.31-32. É inevitável que as ideias de Whitman sobre a camaradagem masculina fossem reconhecidas por muitos como afirmações de homossexualidade, atraindo apoiadores americanos e europeus. Não obstante Whitman ter relutado em reconhecer o conteúdo homossexual em publico há poucas dúvidas a respeito das emoções que ele descreveu. Julgando por suas pinturas, Eakins foi também consciente das ideias de Whitman [...]. Tradução deste autor
} 


\section{O sagrado e o erótico em Alair Gomes}

Outro artista no qual encontramos o pathosformel homoafetivo é Alair Comes (1921 - 1992), brasileiro, engenheiro, filósofo e fotógrafo que dedicou boa parte de seu trabalho a retratação do corpo masculino. Em Alair não é possível encontrar qualquer preocupação em esconder a influência grego-romana de admiração do corpo masculino:

The art I have chiefly, but not exclusively, concentrated on is that of Creece, Roma and Italy in the Renaissance and the previous centuries. My visions of art works and art places, as well of live young men in the countries I visited [...] are commented on in such a way as to gradually outline a basically erotic view of art $\left[\ldots . .{ }^{15}\right.$

O período em que o artista viajou pela Europa (entre agosto e outubro de 1983), gerou uma série de fotos realizadas por Alair em diversos museus europeus de estátuas e seus detalhes; inclusive a série do Davi de Miguel Ângelo e os registros quase filosóficos de seu encontro com essa obra renascentista. Alair, como um sismógrafo, capta a vibração homoerótica presente no trabalho minucioso que Miguel Ângelo realizou e, assim como o escultor, acrescenta seu olhar sobre o sagrado que deriva de sua relação com o cristianismo. A forma como Alair narra sua aproximação do Davi assemelha-se ao contato com um ser divino, sagrado, sem com isso, deixar de fotografá-lo de um ângulo inusitado: de baixo para cima e por entre as pernas dela. Em sua serie Simphony ofErotic Icons, que foi produzida entre 1966 e 1977, há uma sequência de registros de torsos masculinos que são verdadeiras reproduções de imagem helenística do Torso de Belvedere. As imagens fotográficas produzidas por Alair devem ser entendidas em um contexto e interação umas com as outras. São séries fotográficas que possuem ritmo e compõe uma narrativa.

\section{Conclusão}

Este trabalho apontou uma energia homoafetiva em trabalhos de artistas de épocas e países diferentes e a forma como a arte possibilita a manifestação de afetos que por diversas vezes são inviabilizados pela sociedade e como os artistas usam essa potência artística para manifestar seus desejos.

\footnotetext{
15 COMES, Alair. A new sentimental journey. Cosac Naify, São Paulo, 2009. A arte que eu tenho principalmente, mas não exclusivamente, me concentrado é a Grega, Romana e da Itália no Renascimento e dos séculos anteriores. Minhas visões dos trabalhos artísticos e dos lugares da arte, assim como da vida dos jovens homens dos locais em que visitei [...] estão comentadas de um jeito para gradualmente delinear uma visão erótica da arte basicamente [...]. Tradução deste autor.
} 
Os atuais movimentos de luta pela descolonização da arte (por exemplo, movimentos que ressaltam o papel da mulher na arte e movimentos que buscam alternativas à visão eurocêntrica) ao mesmo tempo em que traçam críticas às ortodoxias presentes na História da Arte, essas críticas (que são deveras importantes e apropriadas), constituem-se exógenas às ortodoxias que criticam. A análise proposta neste artigo constitui, ainda que de forma embrionária, uma crítica endógena na medida em que analisa as próprias imagens presentes no cânone e encontra nelas um fator capaz de desagregar as narrativas impostas pelos sistemas constituídos.

Ao utilizar método que Aby Warburg empregou em suas análises para encontrar a resistência das imagens pagãs em pinturas renascentistas, é possível buscar pela sobrevivência da eroticidade entre homens da Antiguidade Grega nas imagens do nu masculino pela História da Arte. Warburg encontrou na imagem da Ninfa a sua nachleben der antigue. A proposta desta pesquisa é pensar na imagem do Eros, com a presença de sua flecha fálica sempre à mão e nunca escondida sob panejamentos. Esse Eros espera ser rememorado em seu lugar filosófico que não pode, nem deve ser reduzido às orientações sexuais apenas. O Eros homoafetivo traz, agora constituído como um pathosformels, uma estética própria vinculada à profunda ética de uma arte homoafetiva, onde o corpo masculino é retratado e despido de seus símbolos de grandeza e heroísmo, tornando-se objeto de desejo e de prazer. O corpo do homem passa à materialidade, podendo assim ser visto, tocado, agredido, desmontado, desconstruído e, finalmente, humanizado. 


\section{Referências Bibliográficas}

AFRAHI, Shahram. Representação do masculino nas artes visuais: performance, pintura, fotografia. Brasília, 2012. Disponível em: http://repositorio.unb.br/handle/10482/11132. Acesso em: 05 Set. 2018.

AGAMBEN, Giorgio. A potência do pensamento: ensaios e conferências. Tradução de Antônio Guerreiro. Editora Autêntica, Belo Horizonte, 2015.

ARBOUR, Renée. Miguel Ângelo. Editora do Minho, Barcelos, 1985.

CLARK, Kenneth. O Nu. Lisboa: Editora Ulisseia, 1956.

COOPER, Emmanuel. The sexual perspective: homosexuality and art in the last 100 years in the West. Routledge \& Kegan Paul, Londres, 1986.

DOVER, Kenneth ]. A homossexualidade na Grécia Antiga. Tradução de Luís Sérgio Krausz. Editora Nova Alexandria, São Paulo, 2007.

ECO, Humberto. História da beleza. Tradução Eliana Aguiar. Record, Rio de Janeiro, 2010.

COMES, Alair. A new sentimental journey. Cosac Naify, São Paulo, 2009.

LISSOVSKY, Maurício. A vida póstuma de Aby Warburg: por que seu pensamento seduz os pesquisadores contemporâneos da imagem? Boletim do Museu Paraense Emílio Goeldi, Ciências Humanas, Belém, v. 9, n. 2, mai-ago. 2014. Disponível em: <http://www.scielo.br/pdf/bgoeldi/vgn2/ao4vgn2.pdf>. Acesso em 22 jun. 2019.

LUCIE-SMITH, Edward. Adam: the male figure in art. Londres: Weidenfeld \& Nicolson, 1998.

NATTER, Tobias G.; LEOPOLD Elisabeth. Nude Men: from 1800 to the present day. Vienna: Hirmer, 2013.

SASLOW, James M. Pictures and passions: a history of homosexuality in the visual arts. Nova lorque: Viking. 1999.

WARBURG, Aby. Histórias de fantasmas para gente grande: escritos, esboços e conferências. 1. ed. Organização: Leopoldo Waizbort; tradução: Lenin Bicudo Bárbara, Companhia das Letras, São Paulo, 2019. 